\title{
Differentiation of Commercial PDO Wines Produced in Istria (Croatia) According to Variety and Harvest Year Based on HS-SPME-GC/MS Volatile Aroma Compound Profiling
}

\author{
Igor Lukić* and Ivana Horvat \\ Institute of Agriculture and Tourism, Karla Huguesa 8, HR-52440 Poreč, Croatia
}

Received: June 30, 2016

Accepted: November 11, 2016

\begin{abstract}
Summary
To differentiate monovarietal wines made from native and introduced varieties in Istria (Croatia), samples of Malvazija istarska, Chardonnay and Muscat yellow from two harvest years (2013 and 2014) were subjected to headspace solid-phase microextraction and gas chromatographic/mass spectrometric analysis (HS-SPME-GC/MS) of volatile aroma compounds. Significant effects of variety and harvest year were determined, but their interaction complicated the differentiation. Particular compounds were consistent as markers of variety in both years: nerol for Malvazija, ethyl cinnamate and a tentatively identified isomer of dimethylbenzaldehyde for Chardonnay, and terpenes for Muscat yellow. Wines from 2013 contained higher concentrations of the majority of important volatiles. A $100 \%$ correct differentiation of Malvazija istarska and Chardonnay wines according to both variety and harvest year was achieved by stepwise linear discriminant analysis.
\end{abstract}

Key words: monovarietal wine, Croatia, volatile aroma compounds, variety, harvest year, HS-SPME-GC/MS

\section{Introduction}

Aroma is probably the most important organoleptic characteristic that defines the typicity and quality of wine. It is one of the crucial factors that determine its market value and price, and a key attribute for consumer preference. Wine aroma results from the occurrence of several hundreds of odouriferous volatile compounds originating from grapes (primary or varietal aromas), compounds produced in fermentation (secondary or fermentation aromas), and, in aged wines, compounds produced during maturation (tertiary aromas) (1). Volatile aroma compounds found in wine pertain to different chemical classes, such as monoterpenes, norisoprenoids, higher alcohols, fatty acids, esters, aldehydes, ketones, benzenoids, etc. (2), and occur in concentrations ranging from ng/L to a few hundreds of $\mathrm{mg} / \mathrm{L}$ (3). The final aroma of a wine is a result of complex interactions between several factors, such as geographical location of the vineyard (4), which is linked to soil and climatic conditions (5), harvest year $(6,7)$, yeast strain (8), production parameters (9), etc. Particular attention has been devoted to the influence of varietal origin, and several studies have focused on the identification of volatile compounds typical for different varieties, important for the expression of varietal characteristics in wine (10-20). The knowledge of the chemical (volatile aroma) composition of varietal wines may give opportunities to producers to deeper understand the phenomena they observe in practice and control the production with greater efficiency to obtain wines with a more pronounced varietal typicity and higher quality. It may enable a proper characterisation and differentiation of varietal wines, attributing them an added marketing value. Wine is globally consumed, and it is a food commodity of relatively high commercial value and importance to the economy of many world countries. Therefore, wine authenticity control, among others, in terms of varietal origin characterisa- 
tion and differentiation, is continuously required to detect adulteration and to improve wine quality (21).

At this moment, the Republic of Croatia is the latest state that has joined the European Union. Like many other Mediterranean countries, it has a vitivinicultural tradition that is centuries long, with today a relatively developed wine industry and rather interesting domestic grape varieties. The quality of Croatian wines in recent years is rapidly and constantly improving, which resulted in significant success on the national and international markets and quality competitions. Their reputation has recently been strengthened by gaining European Protected Designations of Origin (PDO), which certify their authenticity and the connection of their quality with varietal and territorial origin. In the last few decades, Croatian domestic varieties, linked to specific terroirs and adapted to the local environmental conditions, have been used to produce original and high-quality wines and compete on the market with widely spread international varieties to attract consumers, nowadays more and more motivated by marketing attributes and new wine types rather than just pleasant aroma and taste (7).

From a scientific point of view, Croatian wines are poorly characterised when compared to other European and world wines. Because of the lack of objective scientific information, knowledge on the varietal typicity of wines from native Croatian grape varieties is still on an informal level. For example, there is published data on the composition of wines made from Malvazija istarska, the most spread and important native white grape variety in Croatia grown principally in the region of Istria $(9,22-$ $25)$, but the volatile compounds and their particular concentrations, indicators of its varietal origin and drivers of its varietal typicity, on the basis of which it might be distinguished and differentiated from other monovarietal white wines, are still unknown. On the other hand, Chardonnay is a globally spread and known variety, and its wine aroma has been investigated extensively (26-30). Despite many characterisation studies, Chardonnay has rarely been directly confronted with, compared to, and differentiated from other white wines of similar typology, especially from this part of Europe. The compounds responsible for typical Chardonnay aroma have been identified (26-30), but it is still not known if the amounts found are specific for this variety and can differentiate it from other monovarietal wines. A small number of previous differentiation attempts were limited in that they were based only on fermentation-derived compounds (31), comparison with mostly red wines (32), or used only $\mathrm{m} / \mathrm{z}$ fragments after direct injection in an electrospray ionisation Fourier transform mass spectrometer (ESI-FT-MS), without the identification of volatile compounds as discriminating variables (33). Chardonnay wines in question were produced in South Africa, Brasil and Chile, respectively. Wines made from Muscat yellow grapes, another important variety in Croatia especially in the region of Istria, were globally studied extremely rarely, except those produced in Italy, which were investigated extensively, but relatively long ago (34-36).

The main objective of this study is to determine the differences in the composition of volatile aroma compounds between wines made from three important white grape varieties in the Istria region of Croatia (PDO Croatian Istria), through the combined use of HS-SPME-GC/MS profiling with univariate and multivariate statistics. The aim is to contribute to the knowledge on the varietal typicity of the domestic Malvazija istarska wine, as well as its differentiation from wines obtained from internationally known Chardonnay and Muscat yellow wines produced in the same area. Comparison between native Malvazija istarska and introduced Chardonnay is especially interesting and important because these are competing varieties used in Istria to produce typologically similar wines. Further, among the local professional wine community, Malvazija istarska wines are often linked to a so-called subtle 'muscat-like character'. The comparison with Muscat yellow wines in this study might help to clarify this attribute. Interaction of varietal origin with other factors of influence, namely harvest year, may complicate the characterisation, differentiation and authentication of monovarietal wines (37). For this reason, wines from two consecutive harvest years, significantly different with respect to climatic conditions, were included in this study.

\section{Materials and Methods}

\section{Wine samples and harvest years}

Samples of typical fresh, young, unoaked wine Malvazija istarska, Chardonnay and Muscat yellow, with Protected Designation of Origin (PDO Croatian Istria, traditional term: Quality wines), produced by standard winemaking technology (destemmed, crushed and mashed grapes, without or up to 24-hour skin contact, inoculation with commercial Saccharomyces cerevisiae yeast, and fermentation in stainless steel tanks at temperatures lower than $18{ }^{\circ} \mathrm{C}$ ) were voluntarily consigned by the local producers in the Istria region of Croatia. After an informal preliminary sensory assessment of a larger number of wines, the most typical samples were chosen by a consensus of professional, highly experienced and certified wine tasters from the Institute of Agriculture and Tourism, Poreč, Croatia, on the basis of their personal varietal typicity concept. Five samples of each variety, from each of the two consecutive harvest seasons (2013 and 2014), were collected (total of 30 wines). The two studied harvests were rather different considering climatic conditions. According to the Croatian Meteorological and Hydrological State Institute, in the period from April to September 2013 , the sum of the effective temperatures was $1806^{\circ} \mathrm{C}$, while the total rainfall amounted to $359 \mathrm{~mm}$. Most of the rainfall was recorded in August $(112 \mathrm{~mm})$. In the same period in 2014, the sum of the effective temperatures was lower, $1683^{\circ} \mathrm{C}$, while the total rainfall was much higher: $546 \mathrm{~mm}$. Most of the rainfall was recorded in July (154 $\mathrm{mm}$ ) and September (128 mm). Because of the lower temperatures and lots of rain, 2014 was characterised by problematic and late ripening.

\section{Chemical standards and standard solutions of volatile aroma compounds}

Pure standards of individual volatile aroma compounds were purchased from Merck (Darmstadt, Germany), Sigma-Aldrich (St. Louis, MO, USA), and Fluka (Buchs, 
Switzerland). Stock standard solutions were prepared in ethanol. Working standard solutions were prepared by dilution of stock standard solutions in synthetic wine containing $12 \%$ of ethanol, $5 \mathrm{~g} / \mathrm{L}$ of tartaric acid, $50 \mathrm{mg} / \mathrm{L}$ of each acetaldehyde, methanol, ethyl acetate, 1-propanol and isobutanol, and $150 \mathrm{mg} / \mathrm{L}$ of isoamyl alcohol. Working solutions were adjusted to $\mathrm{pH}=3.2$ with $0.1 \mathrm{M} \mathrm{NaOH}$.

\section{Analysis of volatile aroma compounds by headspace solid-phase microextraction with gas chromatography/ mass spectrometry}

Volatile aroma compounds were isolated using headspace solid-phase microextraction (HS-SPME) according to the modified method of Noguerol-Pato et al. (38), and analysed by gas chromatography/mass spectrometry (GC/MS). SPME fibre holder and 50/30 nm divinylbenzene-carboxen-polydimethylsiloxane (DVB-CAR-PDMS) fibres were purchased from Supelco (Bellefonte, PA, USA). Wine sample was diluted fourfold, and $4 \mathrm{~mL}$ of the solution were placed in a $10-\mathrm{mL}$ glass vial. A volume of $50 \mu \mathrm{L}$ of internal standard solution $(0.84 \mathrm{mg}$ of 2 -octanol per $\mathrm{L}$ of wine for determination of terpenes, norisoprenoids, alcohols and miscellaneous compounds, $0.82 \mathrm{mg}$ of methyl nonanoate per L of wine for determination of esters, and $2.57 \mathrm{mg}$ of heptanoic acid per L of wine for determination of acids) and $1 \mathrm{~g}$ of ammonium sulphate were added. The vial was sealed with a Teflon-faced septum cap, and the sample was pre-conditioned at $40{ }^{\circ} \mathrm{C}$ for $15 \mathrm{~min}$. Microextraction lasted for $40 \mathrm{~min}$ at $40{ }^{\circ} \mathrm{C}$ with stirring $(800 \mathrm{rpm})$. For desorption, the fibre was inserted into the GC/MS injector port at $248^{\circ} \mathrm{C}$ for $5 \mathrm{~min}(3 \mathrm{~min}$ in splitless mode).

Identification and quantification of minor volatile compounds was performed using a Varian 3900 gas chromatograph coupled with a Varian Saturn 2100T ion trap mass spectrometer (Varian Inc., Harbour City, CA, USA). The column used was an Rtx-WAX $(60 \mathrm{~m} \times 0.25 \mathrm{~mm}$ i.d., $0.25 \mu \mathrm{m}$ film thickness; Restek, Bellefonte, PA, USA). Initial oven temperature was $40{ }^{\circ} \mathrm{C}$, then increased at $2{ }^{\circ} \mathrm{C}$ / min to $240{ }^{\circ} \mathrm{C}$, and then kept at $240{ }^{\circ} \mathrm{C}$ for $10 \mathrm{~min}$. Injector, transfer line and ion trap temperatures were 245, 180 and $120^{\circ} \mathrm{C}$, respectively. Mass spectra were acquired in electron impact mode $(70 \mathrm{eV})$ at $1 \mathrm{~s} / \mathrm{scan}$, full scan with a range of $m / z=30-450$. The carrier gas was helium ( $1 \mathrm{~mL} /$ min). Identification was performed by comparing retention times and mass spectra with those of pure standards when available, and with mass spectra from NIST05 library (National Institute of Standards and Technology, Gaithersburg, MD, USA). Identification by comparison with mass spectra was considered successful for compounds with the MS spectra reverse match numbers higher than 800. Linear retention indices (relative to $n$-alkanes from $C_{10}$ to $C_{28}$ ) were calculated and compared to those from literature (22,39-44). When standards were available, standard calibration curves were constructed. For other compounds semi-quantitative analysis was carried out, and their concentrations were expressed as equivalents of compounds with similar chemical structure for which standards were available, assuming a response factor equal to one: monoterpenes were quantified as linalool equivalents (response factor (RF) of linalool vs. 2-octa- nol: 1.97), $\mathrm{C}_{6}$ compounds as 1-hexanol (RF of 1-hexanol vs. 2-octanol: 0.14), alcohols as 2-octanol, fatty acids as heptanoic acid, ethyl and other esters as ethyl hexanoate (RF of ethyl hexanoate $v s$. methyl nonanoate: 1.71 ), acetate esters as hexyl acetate (RF of hexyl acetate vs. methyl nonanoate: 1.05), and miscellaneous compounds as 2-octanol equivalents.

\section{Odour activity values and aroma compound groups}

Odour activity values (OAV) of volatile aroma compounds were calculated as the quotients of their concentration and the corresponding odour perception threshold from literature (45-48). The OAVs of the compounds that exhibit similar olfactory sensation were grouped based on their odour description, as suggested by Moyano et al. (49). In this work eight groups (also known as series) were established: varietal terpenic, varietal fruity, sweet, fermentative fruity, berry fruit, floral, fatty and green. Such a presentation of wine aroma profile is an approximation and may differ from the results of sensory analysis performed by a panel of trained tasters. However, it is certainly valid for establishing the potential olfactory impact of particular groups and individual compounds. In addition, it greatly reduces the number of variables to be considered, and facilitates the interpretation of results (49).

\section{Statistical analysis}

All experiments were performed in duplicate, and average values were used in further data analysis. Mean values of concentration and standard deviations were calculated from five replicates, i.e. five samples of each investigated variety per harvest year. One- and two-way analyses of variance (ANOVA) and Fisher's least significant difference (LSD) test were used to compare the mean values at the level of significance of $p<0.05$. To differentiate wines according to varietal origin and harvest year, stepwise linear discriminant analysis (SLDA) was applied, using Wilks' lambda as a selection criterion and F-statistic factor to establish the significance of the changes in lambda when a new variable is tested. The prediction capacity of the discriminant model was estimated by cross-validation. Statistical elaboration was carried out using Statistica v. 8.0 software (StatSoft Inc., Tulsa, OK, USA).

\section{Results and Discussion}

The standard physicochemical parameters determined in wines made from Malvazija istarska, Chardonnay and Muscat yellow varieties in 2013 and 2014 are presented in Table 1. One-way analysis of variance (ANOVA) and Fisher's least significant difference (LSD) test were applied to compare the differences between the mean values for each harvest year separately. Two-way ANOVA with factor variety and harvest year was applied to establish if these differences were consistent in the two harvest years, as well as to determine the effect of harvest year. When two years were considered separately, no significant differences were observed, except for the higher concentration of reducing sugars in Muscat yellow group, 
Table 1. Standard physicochemical parameters of Malvazija istarska, Chardonnay and Muscat yellow monovarietal wines produced in 2013 and 2014

\begin{tabular}{|c|c|c|c|c|c|c|c|c|c|}
\hline \multirow{3}{*}{$\begin{array}{l}\text { Physicochemical } \\
\text { parameter }\end{array}$} & \multicolumn{6}{|c|}{ 1-way ANOVA } & & & \\
\hline & \multicolumn{3}{|c|}{2013} & \multicolumn{3}{|c|}{2014} & \multicolumn{3}{|c|}{ 2-way ANOVA } \\
\hline & $\begin{array}{l}\text { Malvazija } \\
\text { istarska }\end{array}$ & Chardonnay & $\begin{array}{l}\text { Muscat } \\
\text { yellow }\end{array}$ & $\begin{array}{l}\text { Malvazija } \\
\text { istarska }\end{array}$ & Chardonnay & $\begin{array}{l}\text { Muscat } \\
\text { yellow }\end{array}$ & $\mathrm{V}$ & Y & I \\
\hline$\varphi($ alcohol $) / \%$ & $13.0 \pm 0.3$ & $12.8 \pm 0.5$ & $12.1 \pm 0.7$ & $12.2 \pm 0.3$ & $12.5 \pm 0.5$ & $12.0 \pm 1.1$ & n.s. & n.s. & n.s. \\
\hline$\gamma($ reducing sugars $) /(\mathrm{g} / \mathrm{L})$ & $(2.6 \pm 1.0)^{\mathrm{b}}$ & $(3.4 \pm 1.2)^{\mathrm{b}}$ & $(29.6 \pm 16.8)^{a}$ & $(2.5 \pm 0.4)^{\mathrm{b}}$ & $(1.7 \pm 0.3)^{\mathrm{b}}$ & $(27.0 \pm 9.0)^{a}$ & * & n.s. & n.s. \\
\hline $\begin{array}{l}\gamma \text { (total dry extract } \\
\text { without sugars }) /(\mathrm{g} / \mathrm{L})\end{array}$ & $19.3 \pm 0.8$ & $20.3 \pm 0.9$ & $20.3 \pm 1.6$ & $21.5 \pm 0.7$ & $21.5 \pm 0.9$ & $22.9 \pm 1.3$ & n.s. & * & n.s. \\
\hline$\gamma(\operatorname{ash}) /(\mathrm{g} / \mathrm{L})$ & $2.0 \pm 0.2$ & $2.2 \pm 0.2$ & $2.5 \pm 0.4$ & $2.6 \pm 0.2$ & $2.5 \pm 0.3$ & $2.5 \pm 0.4$ & n.s. & * & n.s. \\
\hline Total acidity/(g/L) & $5.2 \pm 0.3$ & $5.6 \pm 0.2$ & $5.3 \pm 0.7$ & $6.2 \pm 0.8$ & $6.1 \pm 0.4$ & $6.4 \pm 0.8$ & n.s. & * & n.s. \\
\hline $\mathrm{pH}$ & $3.29 \pm 0.07$ & $3.3 \pm 0.1$ & $3.4 \pm 0.2$ & $3.4 \pm 0.1$ & $3.5 \pm 0.1$ & $3.4 \pm 0.1$ & n.s. & n.s. & n.s. \\
\hline Volatile acidity/(g/L) & $0.28 \pm 0.05$ & $0.27 \pm 0.08$ & $0.33 \pm 0.09$ & $0.25 \pm 0.04$ & $0.26 \pm 0.07$ & $0.3 \pm 0.1$ & n.s. & n.s. & n.s. \\
\hline
\end{tabular}

Results are expressed as mean value \pm standard deviation, $N=5$. Different lowercase letters in superscript in a row represent statistically significant differences between mean values at $\mathrm{p}<0.05$ obtained by one-way ANOVA and Fisher's least significant difference (LSD) test for each harvest year separately.

Two-way ANOVA factors: $\mathrm{V}=$ variety, $\mathrm{Y}=$ harvest year, I=interaction $(\mathrm{V} \times \mathrm{Y})$; asterisk represents a statistically significant effect at $\mathrm{p}<0.05$ by 2-way ANOVA; n.s.=not significant

which was expected since it consisted of dry, semi-dry, and semi-sweet wines. Two-way ANOVA revealed significant differences, with higher concentrations of extract and ash, and higher total acidity found in wines from 2014.

The concentrations of volatile aroma compounds determined by HS-SPME-GC/MS analysis in wines made from Malvazija istarska, Chardonnay and Muscat yellow varieties in 2013 and 2014 are presented in Table 2.

\section{Varietal aroma compounds}

Terpenic compounds originate from grapes, both as free volatile molecules and released from glycosidic precursors. As expected, Muscat yellow wines were the most abundant in terpenes, both qualitatively and quantitatively, with the domination of exceptionally high linalool concentration (Table 2). Such a composition is relatively in agreement with that previously determined in Muscat yellow must $(34,35)$ and wine $(36)$, where linalool concentrations were higher than $2500 \mu \mathrm{g} / \mathrm{L}$ in some cases. In this work, terpenic diols and particular other terpenes (hydroxyl forms) were not found probably because of their weaker volatility, which is also the reason why the concentration of linalool oxides was probably underestimated during semi-quantitative analysis relative to highly volatile linalool. On the other hand, the occurrence of many other monoterpenes in Muscat yellow wines, such as epoxylinalool, trans- $\beta$-ocimene, 6,10-dihydromyrcenol, menthol and trans-nerolidol has, to our knowledge, been confirmed for the first time.

In 2013, several monoterpenes, such as epoxylinalool, $\beta$-pinene, nerol oxide, and major monoterpenols linalool, hotrienol, $\alpha$-terpineol, nerol and geraniol, were found in significantly higher concentrations in Malvazija istarska than in Chardonnay wines. Nerol emerged as a consistent differentiator of Malvazija and Chardonnay, with significant difference determined in both years. The concentrations and the composition of monoterpenes in Malvazija wines were generally in fair agreement with those report- ed previously: their content was moderate but significant, with linalool followed by geraniol as the most abundant $(9,22-25)$. Although relatively high concentrations of linalool were found in particular Chardonnay wines from other world regions (up to $142 \mu \mathrm{g} / \mathrm{L}$ ), wines from this variety are mostly deficient in monoterpenes (30), and the results of this study confirmed it.

The effect of variety was found to be significant for the majority of terpenes by two-way ANOVA, mostly due to significantly higher levels in Muscat wines (Table 2). The effect of year was also established for many terpenic compounds, with higher amounts generally found in wines produced in harvest 2013, which was characterised by more favourable climatic conditions. The response of each variety to climatic conditions of the two harvest years was different; the effect of year was more evident in Muscat and Malvazija wines, and less in Chardonnay. This was confirmed by significant interaction effects on several terpenes (Table 2). Interestingly, the effect of harvest year was not significant for the majority of the most important, major monoterpenols.

$\mathrm{C}_{13}$ norisoprenoid $\beta$-damascenone derives from the degradation of carotenoid molecules, such as $\beta$-carotene, lutein, neoxanthin and violaxanthin, during fermentation (50), and has an important positive role in wine varietal aroma because of its low odour perception threshold and pleasant odour reminiscent of honey, dried plum, and stewed apple. It was previously reported among the important contributors of both Malvazija istarska $(22,23)$ and Chardonnay aroma (26,30). Significant differences between its content in the investigated monovarietal wines were not found. Such a result confirmed that the levels of $\beta$-damascenone are more dependent on viticultural and winemaking conditions than on variety (50).

$\mathrm{C}_{6}$ compounds are mostly formed during prefermentation production steps by the enzymatic degradation of unsaturated fatty acids and from glycosidic precursors. They contribute to wine aroma with vegetal and herba- 


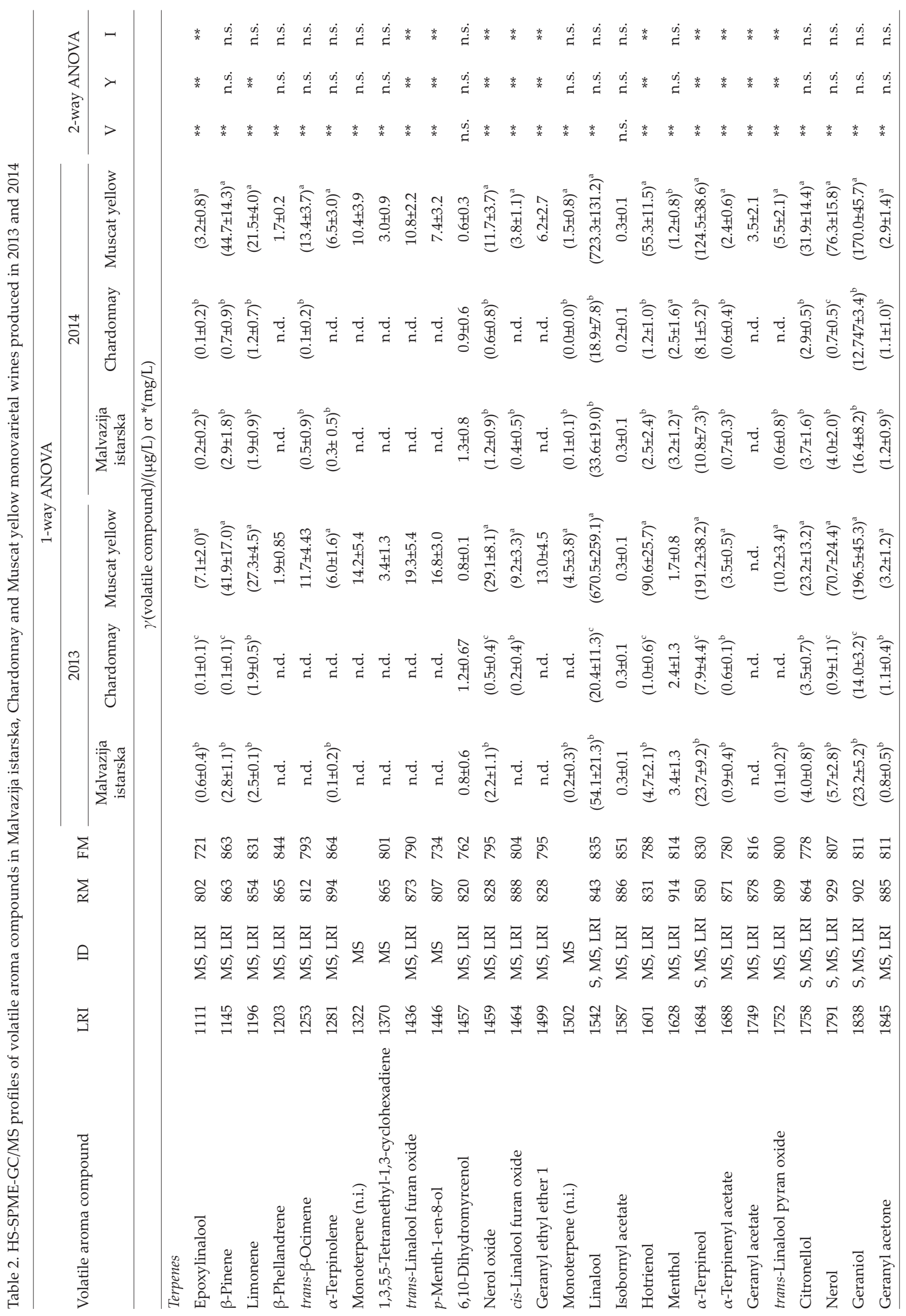




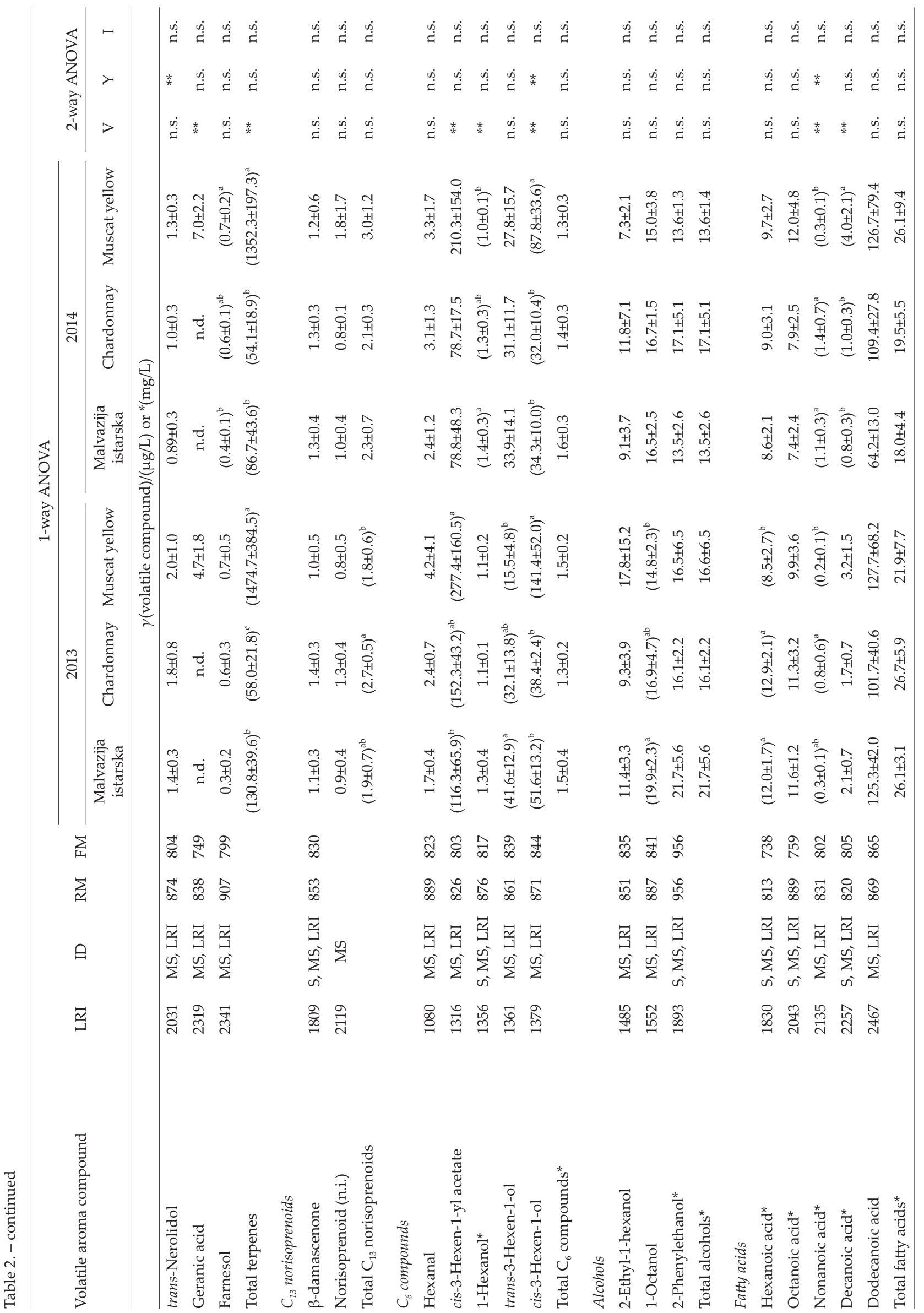




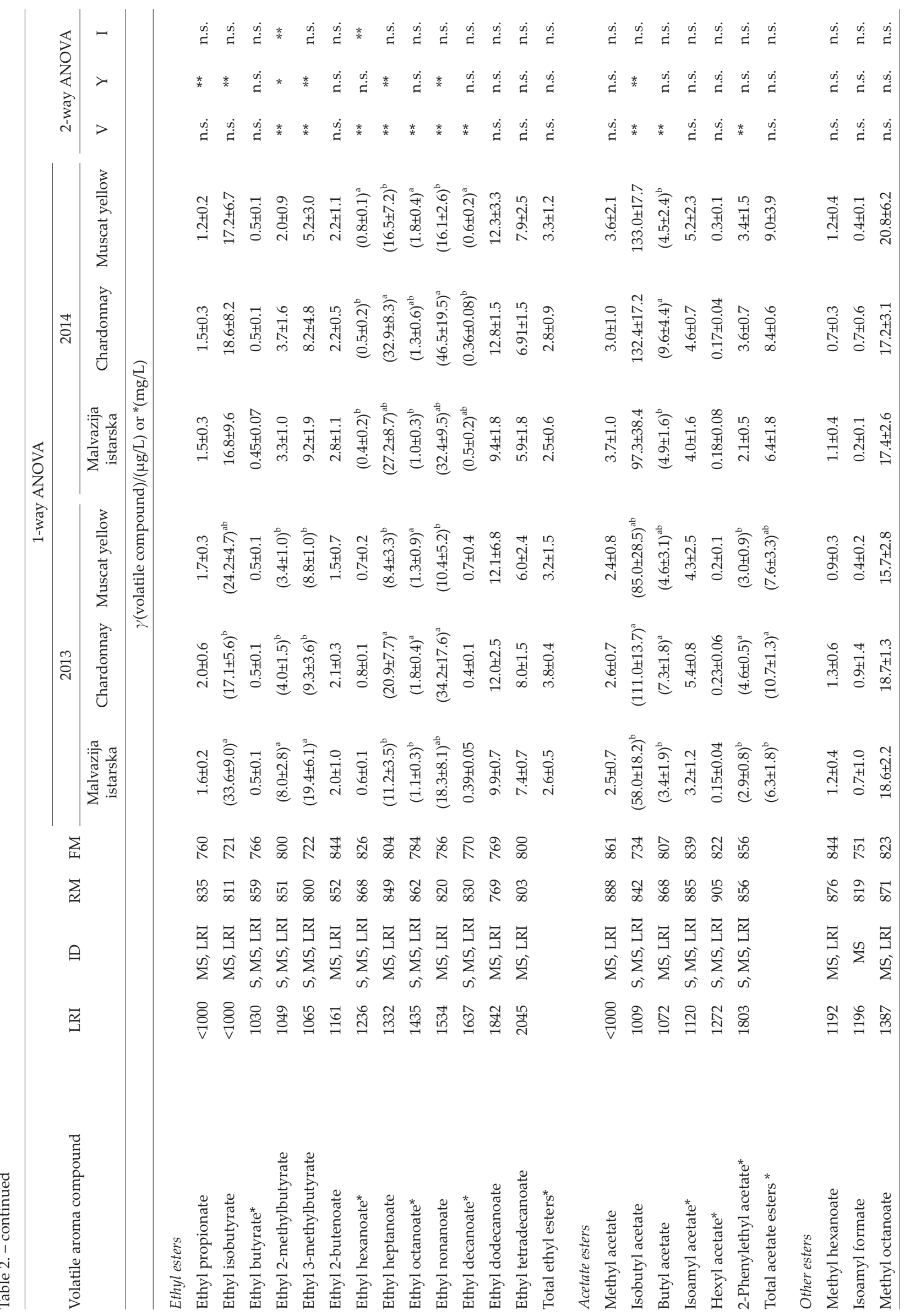




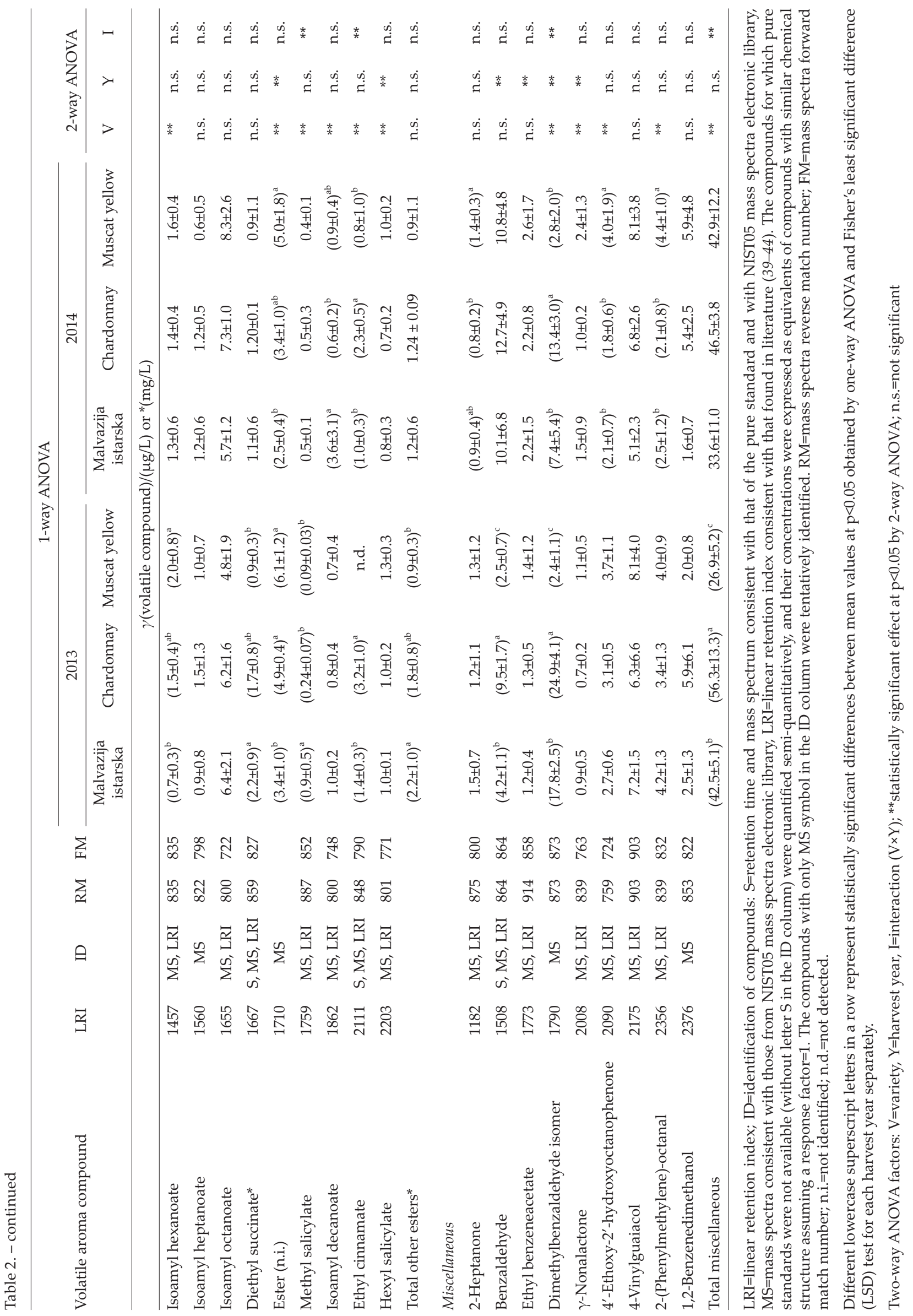


ceous odours, and may have a negative effect when present in high concentration. Some authors consider $\mathrm{C}_{6}$ compounds to be varietal aromas (13), and their ratios were shown to be useful for varietal differentiation of certain wines (19). In this work, significantly higher concentrations of cis-3-hexenyl derivatives (in both years) and lower concentrations of trans-3-hexen-1-ol and 1-hexanol (in 2013 and 2014, respectively) were noted in Muscat yellow than in other investigated monovarietal wines (Table 2).

Other compounds originating from grapes, polyfunctional thiols, have also been identified in Chardonnay wines in earlier investigations, but their impact was not found to be as important as in the case of Sauvignon blanc, where they are crucial for typical varietal aroma (30). Analysis of thiols is not a trivial task because of their very low abundance and reactivity, and this may account for the fact that their occurrence in Malvazija istarska and Muscat yellow has not been confirmed up to date. Although thiols were targeted compounds in this work (standards were available), they were not identified in any of the wines by the HS-SPME-GC/MS method.

\section{Fermentation aroma compounds}

Concentrations and the composition of wine major aroma compounds produced during fermentation, such as alcohols, straight-chain acids, and ethyl and acetate esters, were in a fair agreement with those found in the three varieties investigated earlier $(22,23,30,31,51)$, and it was confirmed that they make up a basis of the aroma profile of unoaked young white wines. They depend mostly on fermentation parameters and conditions, although physicochemical composition of must may have a certain influence (52). Several studies reported that fermentation aroma compound composition significantly depends on varietal origin and harvest year, and can be useful in differentiating wines on the basis of these two criteria $(7,37)$. This especially refers to medium-chain fatty acids and their ethyl esters which, unlike acetates, depend more on the availability of substrates, and therefore agricultural conditions and variety, than on enzymatic activity of yeast (31). For example, it was shown that South African unoaked young Chardonnay wines can be discriminated from other varieties (correct classification of $74 \%$ ) on the basis of 2-phenylethanol, diethyl succinate, ethyl hexanoate, ethyl decanoate, ethyl octanoate, hexyl acetate and 1-propanol concentrations (31).

The concentrations of major straight-chain acids (C6, $\mathrm{C} 8$ and $\mathrm{C} 10$ ) were notable in all wines, surpassing their odour perception thresholds of 420, 500 and $1000 \mu \mathrm{g} / \mathrm{L}$, respectively (45). Fatty acid production is determined in part by the initial composition of must (53). Significant differences among varieties were found in hexanoic and decanoic acid, but in different harvests, implying the effect of harvest year. Low levels of nonanoic acid emerged as a potentially typical feature of Muscat yellow wines (Table 2). The effect of harvest year (two-way ANOVA) was also significant for this acid, with higher concentrations found in wines from 2014.

In 2013, Malvazija istarska wines stood out with higher concentrations of short, branched-chain ethyl esters, but contained lower ethyl octanoate concentration than other investigated wines. In 2014, Muscat yellow wines had the highest concentration of major middle-chain ethyl esters (hexanoate, octanoate and decanoate). Ethyl esters with odd number of carbon atoms (heptanoate and nonanoate) were found useful in differentiating Chardonnay from Muscat yellow wines, being more abundant in the former. Two-way ANOVA results showed a significant effect of variety on the concentrations of major straight-chain ethyl esters, while the effect of harvest year was observed on the majority of branched-chain ethyl esters, with higher concentrations noted in 2013. These compounds, together with higher alcohol acetates, derive mainly from the yeast amino acid metabolism, and it is well known that the concentration of amino acids in grape depends on climatic conditions (7). The effect of year was also significant on odd-chain ethyl esters, with significantly higher concentrations in wines from the less favourable harvest of 2014. Odd-chain ethyl esters basically followed the same pattern observed for the odd-chain fatty acids (Table 2).

Chardonnay wines were more abundant in acetate esters, with significant differences in some cases, more pronounced in 2013. In both harvest years, significant differences were found in a few other esters, in some cases corroborated by two-way ANOVA results. Ethyl cinnamate emerged as a consistent differentiator of Malvazija istarska and Chardonnay wines, with higher concentration in the latter. Such a result partly confirmed previous findings in which ethyl cinnamate was among the key compounds responsible for the typical aroma of Chardonnay $(26,27)$. It is worth mentioning that the chromatographic peak of ethyl cinnamate in Muscat yellow wines interfered with a much larger signal belonging to an unknown compound, which obstructed its identification and quantification in the majority of samples.

Among other compounds, particular benzenoids were found to be characteristic for Chardonnay, especially in 2013 when they were able to differentiate all three wines according to varietal origin. Like ethyl cinnamate, a tentatively identified dimethylbenzaldehyde isomer, with mass spectra showing a rather high degree of similarity with that of 2,4-dimethylbenzaldehyde (characteristic ions with m/z (relative intensity): 133 (100), 134 (41), 105 (35), 77 (16), 75 (15), with mass spectra forward and reverse match number of 873), for which the standard was available, turned out to be a potentially consistent differentiator of Chardonnay wines in both years. Muscat yellow wines had higher levels of tentatively identified 4'-ethoxy-2'-hydroxyoctanophenone and 2-(phenylmethylene)-octanal in 2014. A significant effect of year was observed in the case of benzaldehyde, ethyl benzeneacetate, and $\gamma$-nonalactone with higher amounts found in wines from the rainy 2014. On the other hand, Malvazija istarska and Chardonnay wines from 2013 contained more dimethylbenzaldehyde than in 2014.

Although particular volatile compounds, such as linalool $(26,27,29)$, $\alpha$-terpineol (26), $\beta$-damascenone (26), hexanoic (26), octanoic (26), and decanoic acid $(26,29)$, ethyl butyrate $(26,27)$, ethyl 2-methylbutyrate $(26,27)$, ethyl hexanoate $(26,27)$, isoamyl acetate $(26,29), 2$-phenethyl acetate (26), diethyl succinate (31) and 4-vinylguaiacol (26-28), had previously been counted among the compounds important for unoaked Chardonnay wine typicity (28), in- 
cluded among the key Chardonnay volatiles (26) and found to be decisive for the reconstitution of Chardonnay typical aroma (29), the results of this investigation showed that their amounts are probably not Chardonnay-specific, since they were not found useful as differentiators from Malvazija and/or Muscat yellow wines (Table 2).

\section{Stepwise linear discriminant analysis}

Aromatic Muscat yellow wines were clearly differentiated from relatively neutral Malvazija istarska and Chardonnay by (mono)terpene concentrations higher by an order of magnitude (Table 2). For this reason, further investigation was focused on determining the difference between the latter two, and stepwise linear discriminant analysis (SLDA) was applied only on the Malvazija istarska and Chardonnay data set. The number of groups was four, since wines from the same variety from different harvest year were considered as separate groups. SLDA model extracted 12 compounds according to Wilks' lambda criterion, and was successful in classifying wines according to both varietal origin and harvest year. A $100 \%$ correct classification was achieved after the inclusion of only four compounds in the following order: dimethylbenzaldehyde, isobutyl acetate, $\beta$-pinene, and trans-3-hexen-1-ol. The projection of monovarietal Malvazija istarska and Chardonnay wine samples classified according to variety and harvest year in two-dimensional space defined by the first two discriminant functions, as well as the compounds included in the model are shown in Fig. 1. The samples were grouped according to variety along the direction of the second, and according to harvest year along the direction of the first discriminant function. The prediction capacity of the SLDA model was evaluated by 'leave one-out' cross-validation, where each wine was removed from the model and classified by the functions derived from all cases other than that case. The percentage of correct prediction by cross-validation was also $100 \%$.

When SLDA was applied to the set of Malvazija istarska and Chardonnay samples divided into two groups based on variety, the obtained model included 16 compounds in total. Ethyl cinnamate entered the model as the first, emerging as the most potent differentiator, and classified correctly all Malvazija wines. The inclusion of butyl acetate and 1,2-benzenedimethanol resulted in a $100 \%$ correct classification of all wines. When two groups were formed with harvest year as a criterion, only two compounds were sufficient for a $100 \%$ correct classification: dimethylbenzaldehyde and isobutyl acetate. Another 13 compounds entered and additionally improved the differentiation capacity of the model.

\section{Impact odourants and aroma groups}

One- and two-way ANOVA followed by SLDA analysis extracted many possible markers of varietal origin of Malvazija istarska, Chardonnay and Muscat yellow wines among the analysed volatile compounds. The differentiation was rather clear when considering Muscat wines, clearly distinguished from others by high concentrations of odouriferous monoterpenols (Table 2), which significantly surpassed the corresponding odour perception thresholds in the majority of samples from both years (linalool threshold 6, citronellol 18, nerol 15 and geraniol 30 $\mu \mathrm{g} / \mathrm{L})(46-48)$. It can be stated with certitude that the aroma of Muscat yellow wines was typically muscat. To explain the differences between aroma profiles of Malvazija istarska and Chardonnay, two typologically similar wines, represented a more challenging task. Many of the compounds found to discriminate those wines in this work are of doubtful or unknown sensory impact. In an attempt to approximate how the differences in chemical composition between Malvazija istarska and Chardonnay wines possibly reflect on their sensory quality, the quantified main odourants occurring in peri- and suprathreshold concentrations, and therefore exhibiting odour activity values (OAV) near and higher than 1, were selected and grouped into main aroma groups based on the similarity of their odours. Selected odourants are listed in Table 3 together with their odour descriptors and affiliation to corresponding aroma groups, while the constructed aroma group profiles are presented in Fig. 2.

The dominance of fruity aroma compounds formed in fermentation with ethyl octanoate as the most powerful odourant was determined in all wines (Fig. 2), and corresponded to a profile of a standard young white wine and previous findings on Malvazija and Chardonnay $(22,23,51)$. Many of the esters formed in fermentation contributed to the formation of sweet aroma group, which
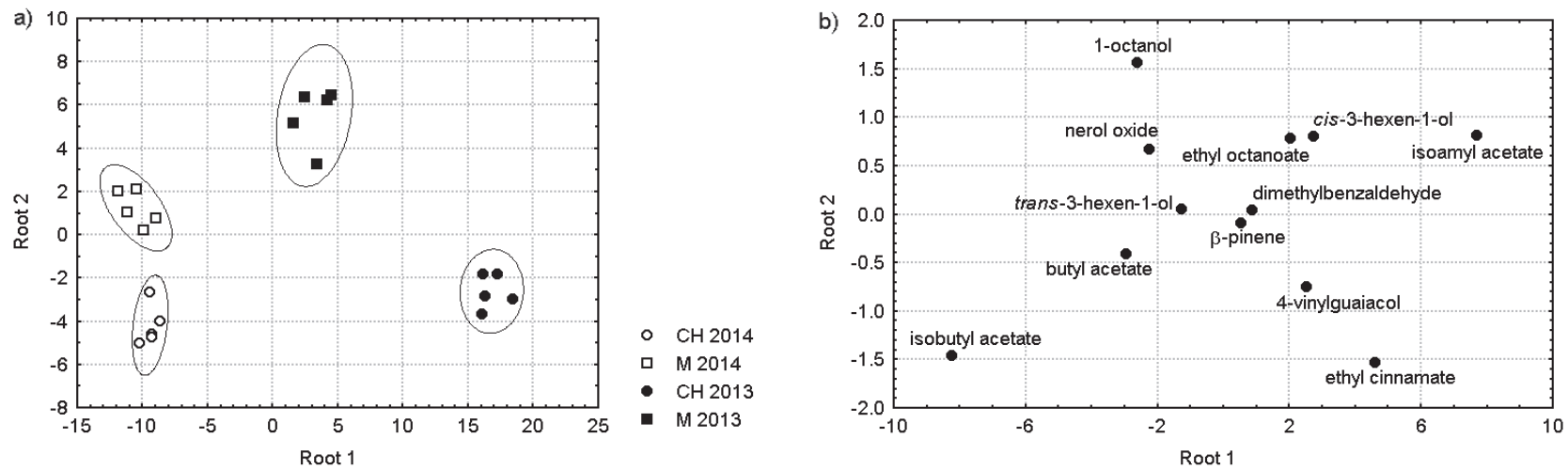

Fig. 1. Projection of Malvazija istarska (M) and Chardonnay (CH) monovarietal wines produced in 2013 and 2014, classified according to varietal origin and harvest year, along the directions of two discriminant functions by stepwise linear discriminant analysis (SLDA) (a), and standardised coefficients of compounds selected by the SLDA model (b) 
Table 3. Odour perception thresholds (OPT) and odour descriptors (45-48), and aroma group affiliation of the main odourants found in Malvazija istarska and Chardonnay monovarietal wines produced in 2013 and 2014

\begin{tabular}{|c|c|c|c|}
\hline Odourant & $\mathrm{OPT} /(\mu \mathrm{g} / \mathrm{L})$ & Odour descriptor & Aroma group \\
\hline Linalool & 6 & floral & varietal terpenic, floral \\
\hline Citronellol & 18 & citrus & varietal terpenic, varietal fruity \\
\hline Nerol & 15 & orange flowers, rose & varietal terpenic, floral \\
\hline Geraniol & 30 & roses, geranium & varietal terpenic, floral \\
\hline$\beta$-Damascenone & 0.05 & sweet, stewed apple, plum & varietal fruity, sweet \\
\hline 1-Hexanol & 1620 & fresh cut grass & green \\
\hline cis-3-Hexen-1-ol & 70 & grass, herbaceous & green \\
\hline 2-Phenylethanol & 10000 & rose, talc, honey & floral \\
\hline Hexanoic acid & 420 & cheese, rancid & fatty \\
\hline Octanoic acid & 500 & cheese, rancid, fat & fatty \\
\hline Decanoic acid & 1000 & rancid, waxen, plasticine & fatty \\
\hline Ethyl isobutyrate & 15 & berry, blackberry & sweet, berry fruit \\
\hline Ethyl butyrate & 20 & fruity & fermentative fruity \\
\hline Ethyl 2-methylbutyrate & 1 & sweet fruit & sweet, berry fruit \\
\hline Ethyl 3-methylbutyrate & 3 & berry, blackberry & sweet, berry fruit \\
\hline Ethyl hexanoate & 5 & green apple & fermentative fruity \\
\hline Ethyl octanoate & 2 & sweet, banana, pineapple & sweet, fermentative fruity \\
\hline Ethyl decanoate & 200 & grape, fruit & fermentative fruity \\
\hline Isoamyl acetate & 30 & banana & fermentative fruity \\
\hline 2-Phenethyl acetate & 250 & fruity, honey, floral & fermentative fruity, floral \\
\hline Ethyl cinnamate & 1 & fruity, honey, cinnamon & sweet, fermentative fruity \\
\hline
\end{tabular}
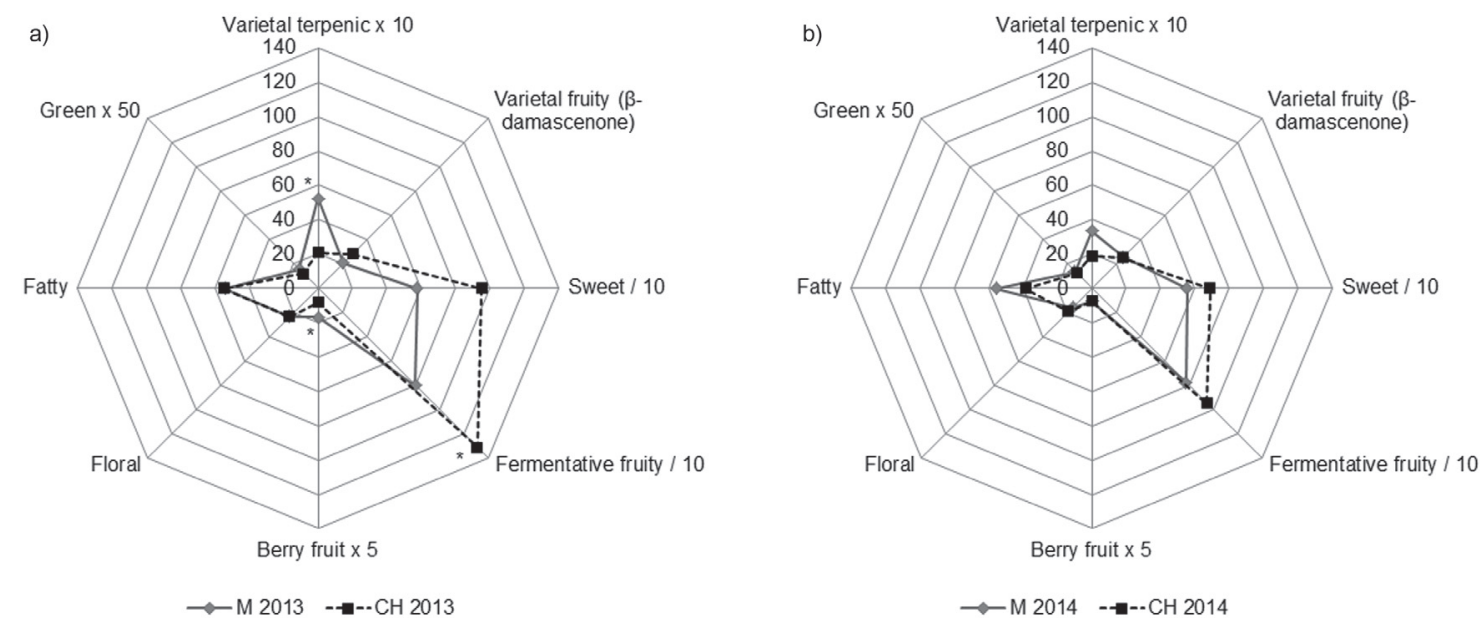

Fig. 2. Aroma profiles of Malvazija istarska (M) and Chardonnay (CH) monovarietal wines produced in 2013 (a) and 2014 (b), obtained on the basis of aroma group values calculated from the odour activity values of the corresponding aroma compounds. Asterisks denote statistically significant differences at $\mathrm{p}<0.05$ obtained by one-way ANOVA and Fisher's least significant difference (LSD). Values of particular aroma group were multiplied or divided by a factor in order to obtain a more uniform display

was also among the dominant aromas. In Chardonnay wines, these two groups had higher values, suggesting that Chardonnay wine aroma was characterised by higher intensities of fruity and sweet odours than that of Malvazija. On the other hand, the profile of Malvazija istarska wines was somewhat more complex, with higher levels of the varietal terpenic group in both years, berry fruit group in 2013 , and fatty group in 2014 . It is possible that the sub- tle, so-called 'muscat character' of Malvazija istarska wines, which is often encountered in practice, derives from the sensory activity of linalool supported by other major monoterpenols through synergistic and additive effects. The effect of harvest year was also evident: varietal terpenic, fruity and sweet groups prevailed in wines from 2013 in relation to those from 2014, implying the former were more aromatic. 


\section{Conclusions}

By using volatile aroma profiles obtained by HS-SPME-GC/MS analysis, elaborated by univariate and multivariate statistics, a detailed characterisation of three monovarietal wines, Malvazija istarska, Chardonnay and Muscat yellow produced in Istria (Croatia) was achieved. Varietal differentiation of wines produced in climatically more favourable harvest of 2013 was more successful, and many compounds emerged as potential discriminators. Colder and humid 2014 exerted a significant effect by partially or totally annulling their differentiating ability, but extracted new markers specific for 2014. It is clear that variety and harvest year did not affect the variability in wine composition independently, but interacted with each other. Nevertheless, particular compounds emerged as statistically consistent markers of varietal origin through both vintages: Malvazija had specific nerol concentration, ethyl cinnamate and a dimethylbenzaldehyde isomer were characteristic for Chardonnay, while Muscat yellow wines were clearly discriminated by the highest concentration of terpenes. It is worth emphasising that several neglected compounds with small or no sensory significance, commonly not listed among wine origin differentiators, such as particular odd-chain acids and esters and benzenoids, were found to have interesting discrimination capacity. Apart from that, it was shown that not only varietal aromas, but several fermentation aroma compounds were significantly affected by variety. Wines from the more favourable harvest of 2013 contained higher concentrations of the majority of important volatile compounds than in 2014. A special attention was given to the comparison of Malvazija istarska and Chardonnay wines, two wines similar by typology, the former being a domestic, and the latter an introduced variety in Istria and Croatia. Malvazija wines were more abundant in monoterpenes, while Chardonnay aroma was characterised by higher concentrations of fruity esters. Such differences were pronounced and statistically significant in wines from 2013, but were partially overpowered by the effect of unfavourable 2014. Despite that, a $100 \%$ correct classification of Malvazija istarska and Chardonnay wines according to both variety and harvest year was achieved by stepwise linear discriminant analysis, confirming that detailed HS-SPME-GC/MS aroma profiling accompanied by multivariate statistics is a powerful tool for differentiation of wines based on various criteria. The concept of odour activity values and aroma groups pointed to the potential differences between sensory profiles of Malvazija istarska and Chardonnay wines.

It is worth emphasising that this study represents the first successful attempt to compare and differentiate Malvazija istarska from other monovarietal white wines, as an important step in determination of its typicity and uniqueness. The study showed that many compounds which had been linked to typical Chardonnay aroma in earlier works have not been confirmed to be Chardonnay-specific, which confirms the importance of varietal differentiation and discrimination analysis, in order to determine the unique varietal characteristics of wines.

It was demonstrated that wine from Malvazija istarska variety is an interesting and viable alternative to common globally known varieties, such as Chardonnay, thus increasing the offer for consumers, and favouring differentiation of Croatian wines on the national and international market. The results obtained are of interest to the industry, and represent useful guidelines for the characterisation and differentiation of Istrian and Croatian monovarietal wines. However, further study is needed, comprising larger sample sets from several vintages. Such an investigation is currently being performed under the framework of a national scientific project.

\section{Acknowledgements}

This work was supported in part by Croatian Science Foundation under the project 'Unravelling the varietal typicity of wines and olive oils from Croatian domestic varieties' (UIP-2014-09-1194).

\section{References}

1. Ribérau-Gayon P, Glories Y, Maujean A, Dubourdieu D. The chemistry of wine: stabilization and treatments. Handbook of enology, vol. 2. Chichester, UK: John Wiley \& Sons Ltd.; 2000.

http://dx.doi.org/10.1002/0470010398

2. Rapp A, Mandery H. Wine aroma. Experientia. 1986;42:87384. http://dx.doi.org/10.1007/BF01941764

3. Castro R, Natera R, Benítez P, Barroso CG. Comparative analysis of volatile compounds of 'fino' sherry wine by rotatory and continuous liquid-liquid extraction and solidphase microextraction in conjunction with gas chromatography-mass spectrometry. Anal Chim Acta. 2004;513:141-50. http://dx.doi.org/10.1016/j.aca.2004.02.002

4. Koundouras S, Marinos V, Gkoulioti A, Kotseridis Y, van Leeuwen CJ. Influence of vineyard location and vine water status on fruit maturation of nonirrigated cv. Agiorgitiko (Vitis vinifera L.). Effects on wine phenolic and aroma components. J Agric Food Chem. 2006;54:5077-86. http://dx.doi.org/10.1021/jf0605446

5. Sabon I, de Revel G, Kotseridis Y, Bertrand A. Determination of volatile compounds in Grenache wines in relation with different terroirs in the Rhone Valley. J Agric Food Chem. 2002;50:6341-5. http://dx.doi.org/10.1021/jf025611k

6. Falqué E, Fernández E, Dubourdieu D. Differentiation of white wines by their aromatic index. Talanta. 2001;54:271-81. http://dx.doi.org/10.1016/S0039-9140(00)00641-X

7. Martínez-Pinilla O, Guadalupe Z, Ayestarán B, Pérez-Magariño $S$, Ortega-Heras M. Characterization of volatile compounds and olfactory profile of red minority varietal wines from La Rioja. J Sci Food Agric. 2013;93:3720-9. http://dx.doi.org/10.1002/jsfa.6211

8. Torrens J, Riu-Aumatell M, López-Tamames E, Buxaderas S. Volatile compounds of red and white wines by headspacesolid-phase microextraction using different fibers. J Chromatogr Sci. 2004;42:310-6. http://dx.doi.org/10.1093/chromsci/42.6.310

9. Radeka S, Herjavec S, Peršurić Đ, Lukić I, Sladonja B. Effect of different maceration treatments on free and bound varietal aroma compounds in wine of Vitis vinifera L. cv. Malvazija istarska bijela. Food Technol Biotechnol. 2008;46:86-92.

10. Câmara JS, Alves MA, Marques JC. Multivariate analysis for the classification and differentiation of Madeira wines according to main grape varieties. Talanta. 2006;68:1512-21. http://dx.doi.org/10.1016/j.talanta.2005.08.012 
11. Gürbüz O, Rouseff JM, Rouseff RL. Comparison of aroma volatiles in commercial Merlot and Cabernet Sauvignon wines using gas chromatography-olfactometry and gas chromatography-mass spectrometry. J Agric Food Chem. 2006; 54:3990-6.

http://dx.doi.org/10.1021/jf053278p

12. Gómez García-Carpintero E, Sánchez-Palomo E, Gómez Gallego MA, González-Viñas MA. Volatile and sensory characterization of red wines from cv. Moravia Agria minority grape variety cultivated in La Mancha region over five consecutive vintages. Food Res Int. 2011;44:1549-60. http://dx.doi.org/10.1016/j.foodres.2011.04.022

13. Gómez García-Carpintero E, Sánchez-Palomo E, Gómez Gallego MA, González-Viñas MA. Free and bound volatile compounds as markers of aromatic typicalness of Moravia Dulce, Rojal and Tortosí red wines. Food Chem. 2012;131:908.

http://dx.doi.org/10.1016/j.foodchem.2011.08.035

14. Fabani MP, Ravera MJA, Wunderlin DA. Markers of typical red wine varieties from the Valley of Tulum (San Juan-Argentina) based on VOCs profile and chemometrics. Food Chem. 2013;141:1055-62. http://dx.doi.org/10.1016/j.foodchem.2013.04.046

15. Rocha SM, Coutinho P, Coelho E, Barros AS, Delgadillo I, Coimbra MA. Relationships between the varietal volatile composition of the musts and white wine aroma quality. A four year feasibility study. LWT - Food Sci Technol. 2010;43: 1508-16. http://dx.doi.org/10.1016/j.lwt.2010.06.007

16. Rodríguez-Bencomo JJ, Cabrera-Valido HM, Pérez-Trujillo JP, Cacho J. Bound aroma compounds of Gual and Listán blanco grape varieties and their influence in the elaborated wines. Food Chem. 2011;127:1153-62. http://dx.doi.org/10.1016/j.foodchem.2011.01.117

17. Sánchez-Palomo E, Gómez García-Carpintero E, Alonso-Villegas R, González-Viñas MA. Characterization of aroma compounds of Verdejo white wines from the La Mancha region by odour activity values. Flavour Fragr J. 2010;25: 456-62.

http://dx.doi.org/10.1002/ffj.2005

18. Urcan DE, Lung ML, Giacosa S, Torchio F, Ferrandino A, Vincenzi S, et al. Phenolic substances, flavor compounds, and textural properties of three native Romanian wine grape varieties. Int J Food Prop. 2016;19:76-98. http://dx.doi.org/10.1080/10942912.2015.1019626

19. Versini G, Orriols I, Dalla Serra A. Aroma components of Galician Albarińo, Loureira and Godello wines. Vitis. 1994; 33:165-70.

20. Vilanova M, Cortés S, Santiago JL, Martínez C, Fernández E. Aromatic compounds in wines produced during fermentation: effect of three red cultivars. Int J Food Prop. 2007;10:86775 . http://dx.doi.org/10.1080/10942910601161615

21. Perestrelo R, Silva C, Câmara JS. A useful approach for the differentiation of wines according to geographical origin based on global volatile patterns. J Sep Sci. 2014;37:1974-81. http://dx.doi.org/10.1002/jssc.201400374

22. Lukić I, Jedrejčić N, Kovačević Ganić K, Staver M, Peršurić $Đ$. Phenolic and aroma composition of white wines produced by prolonged maceration and maturation in wooden barrels. Food Technol Biotechnol. 2015;53:407-18. http://dx.doi.org/10.17113/ftb.53.04.15.4144

23. Lukić I, Plavša T, Sladonja B, Radeka S, Peršurić Đ. Aroma compounds as markers of wine quality in the case of Malvazija istarska young wine. J Food Qual. 2008;31:717-35. http://dx.doi.org/10.1111/j.1745-4557.2008.00230.x

24. Bavčar D, Baša Česnik H, Čuš F, Vanzo A, Gašperlin L, Košmerl T. Impact of alternative skin contact procedures on the aroma composition of white wine. S Afr J Enol Vitic 2011;32:190-203.

25. Bavčar D, Baša Česnik H, Čuš F, Košmerl T. The influence of skin contact during alcoholic fermentation on the aroma composition of Ribolla Gialla and Malvasia Istriana Vitis vinifera (L.) grape wines. Int J Food Sci Technol. 2011;46: 1801-8. http://dx.doi.org/10.1111/j.1365-2621.2011.02679.x

26. Jaffré J, Valentin D, Meunier JM, Siliani A, Bertuccioli M, Le Fur Y. The Chardonnay wine olfactory concept revisited: a stable core of volatile compounds, and fuzzy boundaries. Food Res Int. 2011;44:456-64. http://dx.doi.org/10.1016/j.foodres.2010.09.022

27. Moio L, Schlich P, Etiévant P. Acquisition and analysis of aromagrams of Burgundy wines of Chardonnay grape variety. Sci Aliments. 1994;14:601-8 (in French).

28. Castro Vázquez L, Pérez-Coello MS, Cabezudo MD. Effects of enzyme treatment and skin extraction on varietal volatiles in Spanish wines made from Chardonnay, Muscat, Airén, and Macabeo grapes. Anal Chim Acta. 2002;458:39-44. http://dx.doi.org/10.1016/S0003-2670(01)01521-5

29. Lorrain B, Ballester J, Thomas-Danguin T, Blanquet J, Meunier JM, Le Fur Y. Selection of potential impact odorants and sensory validation of their importance in typical Chardonnay wines. J Agric Food Chem. 2006;54:3973-81. http://dx.doi.org/10.1021/jf052350g

30. Gambetta JM, Bastian SEP, Cozzolino D, Jeffery DW. Factors influencing the aroma composition of Chardonnay wines. J Agric Food Chem. 2014;62:6512-34. http://dx.doi.org/10.1021/jf501945s

31. Louw L, Tredoux AGJ, Van Rensburg P, Kidd M, Naes T, Nieuwoudt HH. Fermentation derived aroma compounds in varietal young wines from South Africa. S Afr J Enol Vitic. 2010;31:213-25.

32. Welke JE, Manfroi V, Zanus M, Lazzarotto M, Alcaraz Zini C. Differentiation of wines according to grape variety using multivariate analysis of comprehensive two-dimensional gas chromatography with time-of-flight mass spectrometric detection data. Food Chem. 2013;141:3897-905. http://dx.doi.org/10.1016/j.foodchem.2013.06.100

33. Villagra E, Santos LS, Vaz BG, Eberlin MN, Laurie VF. Varietal discrimination of Chilean wines by direct injection mass spectrometry analysis combined with multivariate statistics. Food Chem. 2012;131:692-7. http://dx.doi.org/10.1016/j.foodchem.2011.08.078

34. Di Stefano R, Corino L. Comparative evaluation of Muscat blanc and Muscat yellow with particular regard to the terpenic compounds. Riv Vitic Enol. 1984;37:657-70 (in Italian).

35. Di Stefano R, Corino L. Chemical and aromatic characteristics of dry wines produced from Muscato blanc and yellow from Chambave and from Muscat blanc from Canelli. Riv Vitic Enol. 1986;39:3-11 (in Italian).

36. Versini G, Grando MS, Stefanini M, Dellacassa E, Carrau F. Chemical, ampelometric and molecular methods for identification of 'Moscatel miel' from Uruguay as 'Italian Muscat yellow'. Quad Vitic Enol Univ Torino. 1999;23:101-12 (in Italian).

37. Arozarena I, Casp A, Marín R, Navarro M. Multivariate differentiation of Spanish red wines according to region and variety. J Sci Food Agric. 2000;80:1909-17. http://dx.doi.org/10.1002/1097-0010(200010)80:13<1909::AIDJSFA728>3.0.CO;2-U

38. Noguerol-Pato R, González-Barreiro C, Cancho-Grande B, Simal-Gándara J. Quantitative determination and characterisation of the main odourants of Mencía monovarietal red wines. Food Chem. 2009:117;473-84. http://dx.doi.org/10.1016/j.foodchem.2009.04.014 
39. Lukić I, Radeka S, Grozaj N, Staver M, Peršurić Đ. Changes in physico-chemical and volatile aroma compound composition of Gewürztraminer wine as a result of late and ice harvest. Food Chem. 2016;196:1048-57. http://dx.doi.org/10.1016/j.foodchem.2015.10.061

40. Lukić I, Budić-Leto I, Bubola M, Damijanić K, Staver M. Prefermentative cold maceration, saignée, and various thermal treatments as options for modulating volatile aroma and phenol profiles of red wine. Food Chem. 2017;224:251-61. http://dx.doi.org/10.1016/j.foodchem.2016.12.077

41. Perestrelo R, Barros AS, Rocha SM, Câmara JS. Optimisation of solid-phase microextraction combined with gas chromatography-mass spectrometry based methodology to establish the global volatile signature in pulp and skin of Vitis vinifera L. grape varieties. Talanta. 2011;85:1483-93. https://dx.doi.org/10.1016/j.talanta.2011.06.025

42. Giordano M, Zecca O, Belviso S, Reinotti M, Gerbi V, Rolle L. Volatile fingerprint and physico-mechanical properties of 'Muscat blanc' grapes grown in mountain area: a first evidence of the influence of water regimes. Ital J Food Sci. 2013;25:329-38.

43. Scacco A, Lanza CM, Mazzaglia A, Tripodi G, Dima G, Verzera A. Correlation between aroma compounds and sensory properties of passito Malvasia wines produced in Sicily. Am J Enol Vitic. 2010;61:260-5.

44. Vera RR, Chane-Ming J. Chemical composition of the essential oil of marjoram (Origanum majorana L.) from Reunion Island. Food Chem. 1999;66:143-5. https://dx.doi.org/10.1016/S0308-8146(98)00018-1

45. Ferreira V, López R, Cacho JF. Quantitative determination of the odorants of young red wines from different grape varieties. J Sci Food Agric. 2002;80:1659-67. http://dx.doi.org/10.1002/1097-0010(20000901)80:11<1659::AIDJSFA693>3.0.CO;2-6

46. Guth H. Quantitation and sensory studies of character impact odorants of different white wine varieties. J Agric Food
Chem. 1997;45:3027-32.

http://dx.doi.org/10.1021/jf970280a

47. Noguerol-Pato R, González-Álvarez M, González-Barreiro C, Cancho-Grande B, Simal-Gándara J. Evolution of the aromatic profile in Garnacha Tintorera grapes during raisining and comparison with that of the naturally sweet wine obtained. Food Chem. 2013;139:1052-61. http://dx.doi.org/10.1016/j.foodchem.2012.12.048

48. Zalacain A, Marín J, Alonso GL, Salinas MR. Analysis of wine primary aroma compounds by stir bar sorptive extraction. Talanta. 2007;71:1610-5. http://dx.doi.org/10.1016/j.talanta.2006.07.051

49. Moyano L, Zea L, Moreno J, Medina M. Analytical study of aromatic series in sherry wines subjected to biological aging. J Agric Food Chem. 2002;50:7356-61. http://dx.doi.org/10.1021/jf020645d

50. Marais J, van Wyk CJ, Rapp A. Effect of sunlight and shade on norisoprenoids levels in maturing Weisser Riesling and Chenin blanc grapes and Weisser Riesling wines. S Afr J Enol Vitic. 1992;13:23-32.

51. Welke JE, Zanus M, Lazzarotto M, Alcaraz Zini C. Quantitative analysis of headspace volatile compounds using comprehensive two-dimensional gas chromatography and their contribution to the aroma of Chardonnay wine. Food Res Int. 2014;59:85-99. http://dx.doi.org/10.1016/j.foodres.2014.02.002

52. Ugliano M, Henschke PA. Yeasts and wine flavor. In: Moreno-Arribas MV, Polo MC, editors. Wine chemistry and biochemistry. New York, NY, USA: Springer; 2009. pp. 313-92. http://dx.doi.org/10.1007/978-0-387-74118-5_17

53. Schreier P, Jennings WG. Flavor composition of wines: a review. CRC Crit Rev Food Sci Nutr. 1979;12:59-111. http://dx.doi.org/10.1080/10408397909527273 